\title{
A STATE OF AFFAIRS OF EUROPEAN CRIMINOLOGY: AN EXPLORATION OF TOPICS AND TRENDS THROUGH
}

TOPIC MODELLING

Tom Vander Beken ${ }^{1}$, Christophe Vandeviver ${ }^{1,2}$, \& Stijn Daenekindt ${ }^{3}$

${ }^{1}$ Department of Criminology, Criminal Law \& Social Law, Ghent University, 9000 Ghent, Belgium.

${ }^{2}$ Research Foundation-Flanders, 1000 Brussels, Belgium.

${ }^{3}$ Department of Sociology, Ghent University, 9000 Ghent, Belgium.

Direct correspondence to: Tom Vander Beken, Department of Criminology, Criminal Law and Social Law, Ghent University, Universiteitstraat 4, 9000 Ghent, Belgium.

Email: Tom.VanderBeken@UGent.be

Declaration of interest: Tom Vander Beken was President of the European Society of Criminology 20182019, and served on the board of the European Society of Criminology 2017-2020. 


\title{
A STATE OF AFFAIRS OF EUROPEAN CRIMINOLOGY: AN EXPLORATION OF TOPICS AND TRENDS THROUGH
}

\section{TOPIC MODELLING ${ }^{1}$}

\begin{abstract}
What is European criminology about? Through topic modelling, we investigate the content of 11,724 presentations held at the annual conferences of the European Society of Criminology, the largest and most influential professional association in Europe for those who are actively engaged in research, teaching, and/or practice in criminology, from 2001 to 2019. We extract 50 topics, and identify top contributing institutions and countries based on first author institutional affiliation. In addition, we determine the most and least influential topics in European criminology. We further explore how the prominence of topics has evolved over time and identify five topics that are increasingly being addressed and three topics that have gradually lost interest, hot and cold topics respectively. The results are discussed in light of previous research on European criminology and current debates on its epistemology.
\end{abstract}

\section{Keywords:}

Automated text analysis, Big data analysis, Content analysis, Conference abstracts, Systematic review

\section{INTRODUCTION}

What is European criminology? Many have argued what European criminology is, could be or should be (Body-Gendrot et al., 2014; Haen-Marshall, 2001; McAra, 2019; Tonry, 2015; Vander Beken, 2019). None have questioned the need for a European criminology and many have argued its necessity (HaenMarshall, 2001; Schneider, 2001; Tham, 2001). Ultimately, this question drove the foundation of the European Society of Criminology and led to the inception of the European Journal of Criminology. In turn, this boosted the epistemological debate on European criminology and nurtured the development of the discipline (Smith, 2014).

European criminology has been described as "a patchwork quilt, with national orientations and language divisions" (Baars-Schuyt, 2001: 312) that warrants special attention as a separate and special category of criminology relative to US criminology (Tham, 2001). Initially, the debate surrounding the development of a distinct European criminology had a strong emancipatory character. European criminology was to oppose the dominance of US-centered concerns and intellectual agendas in criminology. It was also to do justice to the long standing and excellent criminological activity in Europe and the variety of politics, culture, and social and economic conditions in European countries (Knepper, 2018; Schneider, 2001). The editorial note of the inaugural issue of the European Journal of Criminology listed three factors driving the development of criminology in Europe: the rising profile of crime control, criminal justice and security in European politics, the heightened awareness of human rights issues, and the growing communication between countries across the wider Europe (Smith, 2004). It made the journal opt for an editorial policy to look for "contributions from the widest possible range of European countries, both within and beyond the European Union. Submissions from outside Europe will also be considered if they touch on issues of universal significance or specific European concerns." (Smith, 2004: 14). Notwithstanding the predominant theoretical nature of the epistemological debate on what European criminology is, this "sense of European criminological community" (Ruggiero et al., 1998: 2) has spurred a variety of interesting research activities, publications (see, e.g., Body-Gendrot et al., 2014;

\footnotetext{
${ }^{1}$ This research article is based on the Presidential Address delivered at the meeting of the European Society of Criminology in Ghent, Belgium in September 2019
} 
Smith, 2004), and data collection efforts of all sorts but of which the European Sourcebook of Crime and Criminal Justice Statistics (Killias and Rau, 2000) is probably the most well-known.

Few researchers have taken the efforts to answer the question of what constitutes European criminology and characterises its research a step further. To date, only a handful of researchers have tried to come to a state of affairs of European criminology, explore the practice of doing European criminology, and map what is addressed in European criminological research. At the beginning of the $21^{\text {st }}$ century, BaarsSchuyt (2001) made an overview of criminology in Europe. Based on a questionnaire posted to individuals in 34 European countries, a report on university Institutions of Criminology, an Internet search on selected keywords, and background material available in the WODC library, she identified possibilities for growth, for communication, and for European co-operation. However, the analysis ultimately did not allow her to draw conclusions about the state of criminology in Europe (Baars-Schuyt, 2001: 312).

Other scholars have focused their attention on the content of and citations in the European Journal of Criminology, the official journal of the European Society of Criminology, to make sense of European criminology. Using a variety of analytic approaches, these authors offer an overview of the breadth and width as well as the scholarly influence of European criminology. A number of studies are worth mentioning.

The work done by Smith (2014) is of particular interest for this study. Adhering to the idea that criminology is an enterprise and thus that European criminology is defined by what those who label themselves as European criminologists do, the founding editor of the European Journal of Criminology assessed the state of affairs of European Criminology by reflecting on nine years of publication practices in the journal. Smith (2014) analysed the content of 215 journal articles published in the first nine volumes of the European Journal of Criminology, covering a period between January 2004 and December 2012. He found great specialization in a wide variety of themes. Smith's (2014) thematic analysis showed that youth offending research was the most commonly addressed theme by publications in the European Journal of Criminology. By comparison, research on serious crime, people with longterm criminal careers, organized crime, terrorism, and transnational crime saw little or no interest in the journal. His assessment of the analytic and theoretical approaches adopted in research reported in the journal showed that purely theoretical approaches are rare. Although dominant, empirical approaches are mainly quantitative and Smith (2014: 16) noticed a "tendency to follow an outdated US model of statistical analysis of rather narrow and weak sources of survey data". He reflects on the potential problems of the dominance of quantitative research methods, because the first nine volumes of the European Journal of Criminology saw few qualitative research articles published and argues that the qualitative methods used in most of these articles are unsophisticated. Although a majority of articles addressed in one way or another policy implications of the research, these discussions were found to lack depth and breadth as well as practical applicability. Finally, Smith (2014: 16-17) identifies several avenues along which European criminology could be developed. More research could address the effectiveness of crime prevention programs or interventions to reduce future offending. Future research endeavours could also engage more with serious organized crime, criminal careers, terrorism, and transnational crime. Based on his analysis, he advocates a widening and deepening of European criminology in the second decade of the $21^{\text {st }}$ century. European criminology will increasingly be practiced in a wider range of countries, and European criminologists will engage with a greater variety of subjects and apply novel research methods. At the same time, Smith (2014: 20) anticipates a deepening of European criminology through a closer engagement between humanistic and scientific approaches. 
Citation analysis can, in addition to content analysis, provide further insights on what European criminology is as it is a means to measure scholarly influence (Cohn and Iratzoqui, 2015). At first glance, it is primarily European criminologists who exert scholarly influence on European criminology, at least in terms of publication authorship: the vast majority of articles published in the European Journal of Criminology was authored by scholars affiliated with European institutions (Cohn and Iratzoqui, 2015; Farrington et al., 2019). However, in terms of scholarly influence as measured via raw citations counts and rankings, Cohn and Iratzoqui (2015) paint a different picture. It is American scholars, based on institutional affiliation, who are among the most cited scholars in the European Journal of Criminology. In fact, Cohn and Iratzoqui (2015) find that eight of the ten most cited scholars were affiliated with an American institution, arguing that frequent citation of US-based scholars in the European Journal of Criminology is an indication of their exerting scholarly influence on the development of European criminology. Moreover, Cohn and Iratzoqui (2015) find high concordance rates between the European Journal of Criminology and journals in which American scholars commonly tend to publish such as Criminology.

Notwithstanding the efforts taken by previous scholars to better understand European criminology, there is still much to be learned in terms of the intellectual grounding of European criminology and its evolution. Similar to how Calhoun (2007) argued the importance of studying the growth and development of American sociology, we argue the need to explore how European criminology has grown and changed over time. Indeed, "if science aspires to transcend the limits of surface observation and prejudice, historical understanding of the conditions and trajectories of scientific work can be as valuable as theoretical frameworks and research methods" (Calhoun, 2007: 38). We argue that it is vital to understand how European criminology has developed over time. Not only does engaging with how a discipline evolves allows to identify, shape, and maintain its identity but it is also instructive for training and teaching the discipline to future generations as well as informing current disciplinary practice (Dayé, 2018). Furthermore, it allows to reflect on the discipline's cultural status in contemporary society. However, before one can engage in a discussion of the epistemology of European criminology, we believe that is crucial to gain insight into what that identity could be by exploring how its defined by those who practice European criminology.

In this article, we take another approach at trying to determine what European criminology is. Extant research has analysed the output of or citations in the European Journal of Criminology. While insightful, content and content-creators were analysed separately and only for a limited number of contributions in one specific outlet. In this way, previous analyses have presented a partial image of the status of European Criminology. To contribute to the literature, we address this limitation by analysing the themes presented at the annual conferences of European criminology's leading professional association: the European Society of Criminology. Founded in 2000, the European Society of Criminology is the largest professional association in Europe for criminologists and brings together in Europe all those who are actively engaged in research, teaching, and/or practice in criminology. The Society aims to serve as a forum for disseminating criminological knowledge at a European level. Its annual conferences, in addition to its associated academic journal, the European Journal of Criminology, are its most important instrument to achieve this aim. To achieve this aim, we apply topic modelling, an analytical technique that is well-suited for automated analysis of large text corpora., We extract and classify topics in accepted abstracts and detect how the prevalence of various topics in European criminology changed over time. Not only does this allow us to identify how scholars who participate in the European Society of Criminology define European criminology through their praxis, studying the temporal evolutions in topics can also be a way of determining paradigm shifts and how scholars redefine European criminology as evidenced by the emergence and disappearance of topics. 


\section{DATA AND METHODS}

\section{Data}

The data used in this study consist of all abstracts accepted for presentation at the annual conferences of the European Society of Criminology held from 2001 to 2019. Conference presentations are one of the most important ways in which scholars contribute to advancing their discipline and advocate for their science within a particular discipline. At conferences, scholars will present their most-cutting edge research available and therefore conference presentations give an insight into a discipline's state of affairs (APA Science Student Council, 2007). Abstracts provide concise information on the topic addressed by those presentations and are also the only part of the underlying research presented at a conference that is published in conference proceedings or books of abstracts. The use of abstracts to study academic contributions to a particular journal or field is in line with (Daenekindt and Huisman, 2020; Griffiths and Steyvers, 2004).

With the exception for the 2004 Amsterdam and the 2010 Liège conferences, all abstracts accepted for presentation are archived in annual books of abstracts which are available for download of the European Society of Criminology's website (www.esc-eurocrim.org/index.php/conferences/previousconferences). The abstracts of the 2019 Ghent conference were made available to us by the local organizers of the conference and the book of abstracts is available online through the 2019 conference local website (see https://www.eurocrim2019.com/book-of-abstracts). Abstracts were manually extracted from the books of abstracts and organized in text format. In addition to the abstract title and text, we extracted information on the authors and their affiliation. This resulted in a corpus of 12,927 abstract entries that were considered for inclusion in the analysis. However, entries that lacked an abstract $(\mathrm{N}=1066)$ or had fewer than 50 words $(\mathrm{N}=137)$ were excluded. In total, this resulted in a corpus of 11,724 abstracts corresponding to a total amount of 2,282,493 words and covering 17 annual conferences. The annual number of available abstracts varies considerably between $\mathrm{N}=143$ for the 2001 Lausanne conference and $\mathrm{N}=1317$ for the 2019 Ghent conference with on average 689,65 abstracts per year (Figure 1).

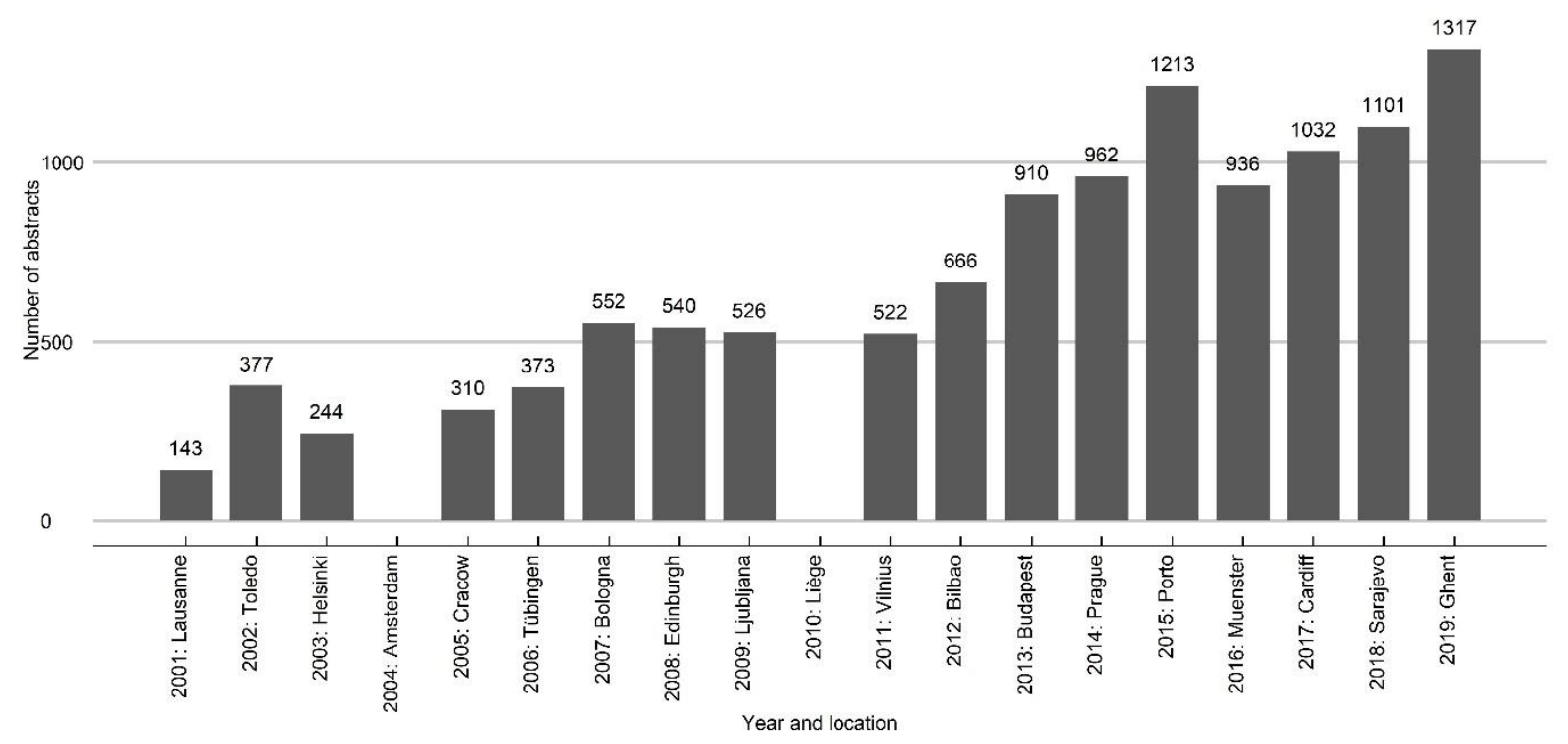

Figure 1. Annual number of abstracts per ESC conference $(N=11,724)$

Prior to analysis, the corpus was pre-processed. This involved replacing all uppercase letters with lowercase letters, and removing white spaces, and punctuation marks from the abstracts. Common 
English-language stop-words such as 'the', 'a', and 'it', were removed from the abstracts because these words complicate the analysis without adding to the results. All words were then stemmed using Porter's word stemming algorithm (Porter, 2001). Stemming reduces complexity without severe loss of information by replacing words with their word stem. For example, 'criminology', 'criminologists', and 'criminologists' were reduced to 'criminolog'. Finally, words that occurred in less than $1 \%$ of the corpus or fewer than 117 abstracts were considered were removed.

\section{Topic modelling}

A reliable content analysis of a large text corpus must be automated to accommodate for the corpus' volume. Furthermore, it must be inductive to ensure that each element of the corpus is treated similarly (DiMaggio et al., 2013). This is essential to avoid bias due to the researchers' position in their discipline and ensure that the outcome of the analysis is not guided by researchers' assumptions with regard to themes in the corpus (Daenekindt and Huisman, 2020; DiMaggio et al., 2013). Topic modelling, the method used in this study, meets these requirements.

Topic models are a suite of text analysis methods designed for the automated extraction of latent thematic structures in large text corpora (Blei and Lafferty, 2009; Steyvers and Griffiths, 2014). Using a large collection of text documents as input, topic models produce sets of interpretable clusters of cooccurring words that are thematically associated, so-called topics. A topic is represented by a set of word probabilities. Combining the words with the highest probabilities on a topic, closely relates to what humans consider a 'theme'. Topic modelling does not require pre-defined codes or categories of meaning like those required to hand-code a text. Instead, researchers specify a number of topics for the algorithm to find based on interpretability and analytic utility (Blei and Lafferty, 2009; Mohr and Bogdanov, 2013). In addition to the word probabilities associated to each topic, the model returns the prevalence of each topic. To be able to interpret the topics generated by the algorithm and to be able to discern meaningful topics from meaningless ones, researchers should have affinity with the phenomena under investigation (Seippel, 2018). In this way, this automated approach to text analysis results in high levels of substantive interpretability and allows researchers to analyse large collections of text by identifying central themes in the corpus (DiMaggio et al., 2013).

We estimate a Correlated Topic Model, which is an extension of Latent Dirichlet Allocation (LDA). Correlated Topic Models relax an assumption of LDA by allowing the occurrence of topics in documents to be correlated (Blei and Lafferty, 2007). In this study, we first estimated models with 10, 30, 50, and 100 topics. The first two authors then evaluated each of these outcomes in terms of their utility for the analysis. As criminologists active in European criminology, we believe that we sufficiently know the field of European criminology to recognize and assess the meaningfulness of a set of topics. Our selection for our final topic model was guided by three criteria. First, European criminology has been operating as a scientific field for at least 20 years with diverse geographical orientations and different scientific traditions and will therefore comprise a larger number of topics. Second, the chosen topic model should allow for reasonable diversity in topics but, third, it should also be narrow enough to enable the interpretation of the extracted topics. Based on this evaluation we have chosen for a 50-topic model.

Within these 50 topics we identified the most and least prevalent topics to determine topic influence throughout the corpus. We further studied the temporal dynamics and evolution of topics by means of a non-parametric trend analysis. The temporal trends allowed us to identify topics that are significantly more prevailing over time within European criminology, so-called 'hot' topics, and topics of which their prominence within European criminology decays over time, so-called 'cold' topics. We use Kendal's tau $(p<.001)$ to identify significant changes in trajectories of topics over time (see, e.g., Giordan et al., 2018; Griffiths and Steyvers, 2004). This temporal trend analysis allows us to illustrate the direction of 
shifts and variations in the topics addressed at the annual conferences of the European Society of Criminology over the last 19 years. The identification of hot topics in science is an attractive application for topic modelling as it provides quantitative measures of the prevalence of particular kinds of research or approaches that may be useful for historical or other scientific or research policy purposes (Griffiths and Steyvers, 2004: 5232).

\section{RESULTS}

\section{Geographic dispersion and institutional affiliation of abstracts}

The information on authorship and affiliation of abstracts allowed us to characterize top contributing countries and institutions to European criminology (based on first authorship). Figure 2 displays the top five contributing institutions and countries (by first authorship) respectively. One in five abstract was first authored by a UK-based scholar. Belgian and German-based scholars are the second and third most prolific abstract authors in our corpus, authoring $7.23 \%$ and $7.04 \%$ of all abstracts respectively. Dutch and Spanish scholars authored $5.61 \%$ and $4.57 \%$ of all abstracts respectively. Taken together, $46 \%$ of all abstracts are authored by scholars from one of the five countries displayed in Figure 2.

There is substantial more variation in the distribution of institutional affiliation across abstracts. The top five contribution institutions account for just $6.76 \%$ of all abstracts. University of Cambridge affiliated scholars are most prolific and have authored $1.74 \%$ of all abstracts, albeit that the difference with scholars from Ghent University is trivial: $1.72 \%$ of all abstracts was authored by Ghent University scholars. Authors affiliated with Free University of Brussels are responsible for $1.30 \%$ of all abstracts. University of Edinburgh and Max Planck Institute affiliated scholars are responsible for 1.02\% and .98\% of all abstract respectively.

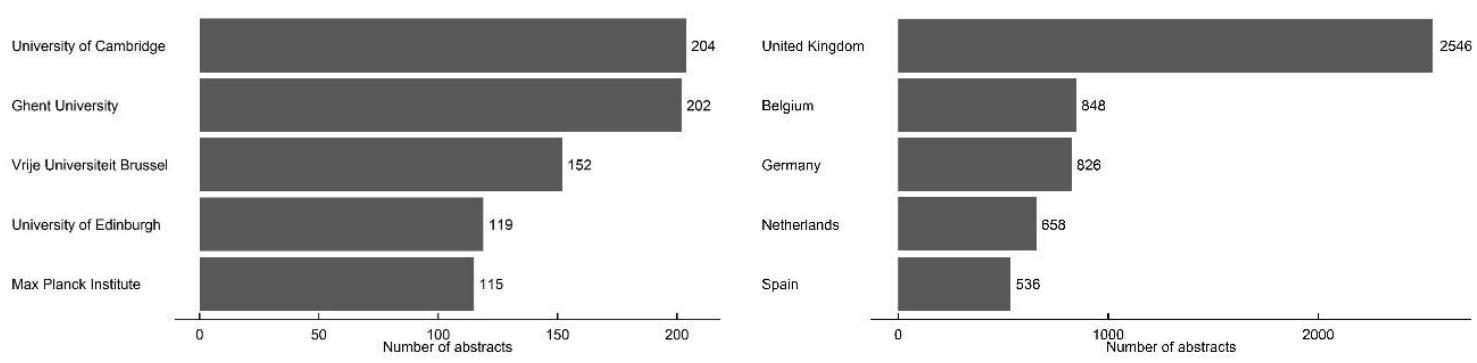

Figure 2. Top five contributing institutions (left) and countries (right) $(N=11,724)$

\section{Overview of topics}

The 50 model solution is presented in Table $1^{2}$. Each list in this table represents a topic and its associated five most probable words as well as its relative prevalence in the corpus and its trend test statistic. We interpreted the topics and labelled each using a combination of inductive reasoning, drawing on wellknown research categories within criminology, and qualitative text analysis of the abstracts that the model identified as the most representative texts for each topic . The extracted topics vary considerably. Some represent general themes in criminology such as prison research (topic 3), risk factors research (40), and youth criminology (topic 41). Other topics are specific such as restorative justice (topic 5), illegal organ trade (topic 39), and self-control theory research (topic 48). Other topics represent methodological approaches to criminological research rather than specific themes such as self-report research (topic 10), characterize thematic approaches within criminology such as gender (topic 28), or capture the vocabulary specific to scientific communication of methods of original research at the annual conferences of the European Society of Criminology (topic 18). Some of the topics we identified extend

\footnotetext{
${ }^{2}$ Topics are presented in no particular order and numbering is used only to identify topics.
} 
the meaning of closely related topics such as spatiotemporal criminology (topic 19), and cities \& neighbourhoods (topic 45), or sexual abuse (topic 20), domestic violence (topic 29), and sexual offending (topic 32).

Table 1. Fifty Topic Solution with topic description, relative prevalence, and Kendall's tau correlation coefficient. ${ }^{*} p<.001$

\begin{tabular}{|c|c|c|c|c|c|c|c|c|c|}
\hline \multirow{2}{*}{\multicolumn{2}{|c|}{$\frac{\text { Topic } 1}{\text { Hate crime }}$}} & \multicolumn{2}{|c|}{ Topic 2} & \multicolumn{2}{|c|}{ Topic 3} & \multicolumn{2}{|c|}{ Topic 4} & \multicolumn{2}{|c|}{ Topic 5} \\
\hline & & \multicolumn{2}{|c|}{$\overline{\text { Gangs }}$} & \multicolumn{2}{|c|}{ Prisons } & \multicolumn{2}{|c|}{ Homicide Rates } & \multicolumn{2}{|c|}{$\begin{array}{c}\text { Restorative } \\
\text { Justice }\end{array}$} \\
\hline Prev. & $\mathbf{T}_{\mathrm{b}}$ & Prev. & $\mathbf{T}_{\mathbf{b}}$ & Prev. & $\mathbf{T}_{b}$ & Prev. & $\mathbf{T}_{\mathrm{b}}$ & Prev. & $\mathbf{T}_{\mathrm{b}}$ \\
\hline $2.10 \%$ & $-.59 *$ & $1.62 \%$ & -.15 & $2.48 \%$ & .26 & $2.33 \%$ & $-.68 *$ & $2.09 \%$ & .26 \\
\hline \multicolumn{2}{|c|}{ [1] crime } & \multicolumn{2}{|c|}{ [1] group } & \multicolumn{2}{|c|}{ [1] prison } & \multicolumn{2}{|l|}{ [1] rate } & \multicolumn{2}{|c|}{ [1] justice } \\
\hline \multicolumn{2}{|c|}{ [2] crimin } & \multicolumn{2}{|c|}{ [2] people } & \multicolumn{2}{|c|}{ [2] release } & \multicolumn{2}{|l|}{ [2] data } & \multicolumn{2}{|c|}{ [2] crimin } \\
\hline \multicolumn{2}{|c|}{ [3] commit } & \multicolumn{2}{|c|}{ [3] member } & \multicolumn{2}{|c|}{ [3] inmat } & \multicolumn{2}{|c|}{ [3] statist } & \multicolumn{2}{|c|}{ [3] system } \\
\hline \multicolumn{2}{|c|}{ [4] hate } & \multicolumn{2}{|c|}{ [4] gang } & [4] impr & & [4] hom & & [4] resto & \\
\hline [5] inclu & & [5] you & & [5] incar & & [5] tren & & [5] pract & \\
\hline$\underline{\text { To }}$ & & & & $\underline{\text { To }}$ & & & & Top & \\
\hline $\begin{array}{r}\bar{M} \\
\text { Laun } \\
\text { Risk As }\end{array}$ & $\begin{array}{l}\text { ey } \\
\text { ring } \\
\text { ssment }\end{array}$ & Sex & ork & Vic & & & & Self-F & orts \\
\hline Prev. & $\mathbf{T}_{\mathbf{b}}$ & Prev. & $\mathbf{T}_{\mathbf{b}}$ & Prev. & $\mathbf{T}_{\mathrm{b}}$ & Prev. & $\mathbf{T}_{\mathbf{b}}$ & Prev. & $\mathbf{T}_{\mathbf{b}}$ \\
\hline $1.71 \%$ & -.18 & $.89 \%$ & .35 & $1.47 \%$ & $.78 *$ & $2.36 \%$ & .31 & $3.54 \%$ & -.44 \\
\hline [1] prev & & [1] wor & & [1] victi & & [1] poli & & [1] studi & \\
\hline [2] asse & & [2] prof & & [2] expe & & [2] offic & & [2] surve & \\
\hline [3] risk & & [3] wor & & [3] supp & & [3] forc & & [3] diffe & \\
\hline [4] polic & & [4] pros & & [4] vuln & & [4] refo & & [4] will & \\
\hline [5] mea & & [5] repr & & [5] need & & [5] wor] & & [5] prese & \\
\hline Tol & 11 & $\underline{\text { To }}$ & & Top & & $\underline{\text { To }}$ & & Top & \\
\hline$\overline{\text { Sent }}$ & $\overline{\operatorname{cing}}$ & & & Corr & $\overline{\text { tion }}$ & Fear $\mathrm{c}$ & Crime & $\overline{\mathrm{Cri}}$ & \\
\hline Prev. & $\mathbf{T}_{\mathbf{b}}$ & Prev. & $\mathbf{T}_{\mathbf{b}}$ & Prev. & $\mathbf{T}_{\mathbf{b}}$ & Prev. & $\mathbf{T}_{\mathbf{b}}$ & Prev. & $\mathbf{T}_{\mathbf{b}}$ \\
\hline $2.15 \%$ & .54 & $.94 \%$ & -.56 & $.85 \%$ & -.37 & $1.11 \%$ & -.49 & $4.01 \%$ & .43 \\
\hline [1] case & & [1] drug & & [1] corrt & & [1] fear & & [1] conc & \\
\hline [2] crim & & [2] use & & [2] anti & & [2] crim & & [2] polic & \\
\hline [3] inve & & [3] alco & & [3] polit & & [3] victi & & [3] polit & \\
\hline [4] cour & & [4] user & & [4] offic & & [4] feel & & [4] $\operatorname{argu}$ & \\
\hline [5] pros & & [5] subs & & [5] publ & & [5] surv & & [5] critic & \\
\hline Tor & 16 & $\underline{\text { To }}$ & & Tor & & $\underline{\text { To }}$ & & Tor & \\
\hline $\begin{array}{r}\text { Traffi } \\
\text { Huma }\end{array}$ & $\begin{array}{l}\text { ing in } \\
\text { Beings }\end{array}$ & Des & ince & $\begin{array}{r}\text { Res } \\
\text { Me } \\
\text { Lan }\end{array}$ & & $\begin{array}{r}\text { Spatio } \\
\text { Crim }\end{array}$ & $\begin{array}{l}\text { pporal } \\
\operatorname{logy}\end{array}$ & Sexua & buse \\
\hline Prev. & $\mathbf{T}_{\mathrm{b}}$ & Prev. & $\mathbf{T}_{\mathrm{b}}$ & Prev. & $\mathbf{T}_{\mathbf{b}}$ & Prev. & $\mathbf{T}_{\mathbf{b}}$ & Prev. & $\mathbf{T}_{b}$ \\
\hline $1.57 \%$ & .54 & $2.49 \%$ & $.90 *$ & $3.92 \%$ & $.73^{*}$ & $2.17 \%$ & -.18 & $1.03 \%$ & .21 \\
\hline [1] right & & [1] inte & & [1] resea & & [1] mod & & [1] repo & \\
\hline [2] hum & & [2] proc & & [2] use & & [2] patt & & [2] sexu & \\
\hline [3] traff & & [3] expe & & [3] data & & [3] use & & [3] abus & \\
\hline [4] prote & & [4] life & & [4] meth & & [4] time & & [4] incid & \\
\hline [5] conv & & [5] desi & & [5] analy & & [5] area & & [5] rape & \\
\hline
\end{tabular}




\begin{tabular}{|c|c|c|c|c|c|c|c|c|c|}
\hline \multirow{2}{*}{\multicolumn{2}{|c|}{$\frac{\text { Topic 21 }}{\text { Sanctions }}$}} & \multicolumn{2}{|c|}{ Topic 22 } & \multicolumn{2}{|c|}{ Topic 23 } & \multicolumn{2}{|c|}{ Topic 24} & \multicolumn{2}{|c|}{ Topic 25} \\
\hline & & \multicolumn{2}{|c|}{ Family } & \multicolumn{2}{|c|}{$\begin{array}{c}\text { Organizational } \\
\text { Crime }\end{array}$} & \multicolumn{2}{|c|}{ Probation } & \multicolumn{2}{|c|}{ Meta-language } \\
\hline Prev. & $\mathbf{T}_{\mathbf{b}}$ & Prev. & $\mathbf{T}_{\mathrm{b}}$ & Prev. & $\mathbf{T}_{\mathbf{b}}$ & Prev. & $\mathbf{T}_{\mathbf{b}}$ & Prev. & $\mathbf{T}_{\mathbf{b}}$ \\
\hline $2.52 \%$ & -.29 & $1.00 \%$ & .35 & $1.22 \%$ & .10 & $3.10 \%$ & -.41 & $4.07 \%$ & -.47 \\
\hline \multicolumn{2}{|c|}{ [1] crimin } & \multicolumn{2}{|c|}{ [1] famili } & \multicolumn{2}{|c|}{ [1] organis } & \multicolumn{2}{|c|}{ [1] communiti } & \multicolumn{2}{|l|}{ [1] one } \\
\hline \multicolumn{2}{|c|}{ [2] punish } & \multicolumn{2}{|c|}{ [2] children } & \multicolumn{2}{|c|}{ [2] sector } & \multicolumn{2}{|c|}{ [2] servic } & \multicolumn{2}{|l|}{ [2] can } \\
\hline \multicolumn{2}{|c|}{ [3] penal } & \multicolumn{2}{|c|}{ [3] parent } & \multicolumn{2}{|c|}{ [3] fraud } & \multicolumn{2}{|c|}{ [3] probat } & \multicolumn{2}{|c|}{ [3] situat } \\
\hline [4] sanc & & [4] chil & & [4] busi & & [4] inter & & [4] plac & \\
\hline [5] legis & & [5] prot & & [5] comp & & [5] prac & & [5] ever & \\
\hline Tor & & To & 27 & Top & & $\underline{\text { To }}$ & & To & \\
\hline Teri & ism & Sent & cing & GeI & & $\begin{array}{l}\text { Dor } \\
\text { Vic }\end{array}$ & & Mig & tion \\
\hline Prev. & $\mathbf{T}_{\mathbf{b}}$ & Prev. & $\mathbf{T}_{\mathbf{b}}$ & Prev. & $\mathbf{T}_{\mathbf{b}}$ & Prev. & $\mathbf{T}_{\mathbf{b}}$ & Prev. & $\mathbf{T}_{\mathbf{b}}$ \\
\hline $1.19 \%$ & .32 & $1.71 \%$ & -.22 & $1.13 \%$ & -.15 & $1.32 \%$ & .24 & $2.04 \%$ & -.49 \\
\hline [1] terro & & [1] sent & & [1] wom & & [1] viol & & [1] cour & \\
\hline [2] attac & & [2] deci & & [2] gend & & [2] dom & & [2] euro & \\
\hline [3] thres & & [3] coul & & [3] fema & & [3] part & & [3] euro & \\
\hline [4] terro & & [4] mak & & [4] male & & [4] viol & & [4] imm & \\
\hline [5] extre & & [5] judg & & [5] men & & [5] perp & & [5] mig & \\
\hline$\underline{\text { Tol }}$ & & $\underline{\text { To }}$ & 32 & Top & & $\underline{\text { To }}$ & & $\underline{\text { To }}$ & 35 \\
\hline Centra & urope & $\begin{array}{r}\text { Se } \\
\text { Off }\end{array}$ & ling & $\begin{array}{l}\text { Intern } \\
\text { Crimi }\end{array}$ & $\begin{array}{l}\text { ional } \\
\text { Law }\end{array}$ & & & $\begin{array}{r}M \\
\text { Crim }\end{array}$ & logy \\
\hline Prev. & $\mathbf{T}_{\mathbf{b}}$ & Prev. & $\mathbf{T}_{\mathbf{b}}$ & Prev. & $\mathbf{T}_{\mathbf{b}}$ & Prev. & $\mathbf{T}_{\mathbf{b}}$ & Prev. & $\mathbf{T}_{\mathbf{b}}$ \\
\hline $2.32 \%$ & -.26 & $1.89 \%$ & $-.63^{*}$ & $2.04 \%$ & .38 & $1.07 \%$ & .22 & $2.78 \%$ & .31 \\
\hline [1] proje & & [1] offe & & [1] law & & [1] scho & & [1] crim & $\log$ \\
\hline [2] pres & & [2] crim & & [2] interl & & [2] educ & & [2] rese & \\
\hline [3] germ & & [3] sex & & [3] enfor & & [3] stud & & [3] field & \\
\hline [4] mair & & [4] offe & & [4] legal & & [4] train & & [4] will & \\
\hline [5] insti & & [5] con & & [5] crimi & & [5] lear! & & [5] scie & \\
\hline Tor & & $\underline{\text { To }}$ & 37 & $\underline{\text { Top }}$ & & $\underline{\text { To }}$ & & To & \\
\hline $\begin{array}{l}\text { UK- } \\
\text { Res }\end{array}$ & $\begin{array}{l}\text { sed } \\
\text { rch }\end{array}$ & $\begin{array}{r}\text { Emo } \\
\text { Beh }\end{array}$ & $\begin{array}{l}\text { ns \& } \\
\text { iour }\end{array}$ & Cybe & rime & $\begin{array}{r}\text { Illega } \\
\mathbf{T}\end{array}$ & rgan & Risk & ctors \\
\hline Prev. & $\mathbf{T}_{\mathbf{b}}$ & Prev. & $\mathbf{T}_{\mathbf{b}}$ & Prev. & $\mathbf{T}_{\mathbf{b}}$ & Prev. & $\mathbf{T}_{\mathbf{b}}$ & Prev. & $\mathbf{T}_{\mathbf{b}}$ \\
\hline $3.96 \%$ & .01 & $2.22 \%$ & .47 & $1.47 \%$ & $.78 *$ & $2.01 \%$ & .29 & $2.25 \%$ & -.31 \\
\hline [1] pape & & [1] behs & & [1] medi & & [1] orga & & [1] fact & \\
\hline [2] will & & [2] effe & & [2] onlin & & [2] acti & & [2] beha & \\
\hline [3] expl & & [3] stud & & [3] techn & & [3] mar & & [3] risk & \\
\hline [4] draw & & [4] emo & & [4] comr & & [4] illeg & & [4] adol & \\
\hline [5] engl & & [5] prog & & [5] interl & & [5] nety & & [5] stud & \\
\hline Tor & & $\underline{\text { To }}$ & 42 & Top & & $\underline{\text { To }}$ & & To & 45 \\
\hline $\begin{array}{r}\mathrm{Y} \\
\text { Crim }\end{array}$ & h & & & Legal & stem & $\begin{array}{r}\text { Crim } \\
\text { Con } \\
\text { So }\end{array}$ & $\begin{array}{l}\text { Srime } \\
\text { \& } \\
\text { ty }\end{array}$ & $\begin{array}{c}\text { Cit } \\
\text { Neighl }\end{array}$ & $\begin{array}{l}\& \\
\text { hoods }\end{array}$ \\
\hline Prev. & $\mathbf{T}_{\mathbf{b}}$ & Prev. & $\mathbf{T}_{\mathbf{b}}$ & Prev. & $\mathbf{T}_{\mathbf{b}}$ & Prev. & $\mathbf{T}_{\mathbf{b}}$ & Prev. & $\mathbf{T}_{\mathbf{b}}$ \\
\hline $1.20 \%$ & -.50 & $2.22 \%$ & -.28 & $1.75 \%$ & -.37 & $3.25 \%$ & .29 & $1.89 \%$ & -.26 \\
\hline
\end{tabular}




\begin{tabular}{|c|c|c|c|c|c|c|c|c|c|}
\hline \multicolumn{2}{|c|}{ [1] juvenil } & \multicolumn{2}{|c|}{ [1] secur } & \multicolumn{2}{|c|}{ [1] system } & \multicolumn{2}{|c|}{ [1] social } & \multicolumn{2}{|c|}{ [1] level } \\
\hline \multicolumn{2}{|c|}{ [2] delinqu } & \multicolumn{2}{|c|}{ [2] public } & \multicolumn{2}{|c|}{ [2] nation } & \multicolumn{2}{|c|}{ [2] culture } & \multicolumn{2}{|c|}{ [2] citi } \\
\hline \multicolumn{2}{|c|}{ [3] youth } & \multicolumn{2}{|c|}{ [3] local } & \multicolumn{2}{|c|}{ [3] end } & \multicolumn{2}{|c|}{ [3] societi } & \multicolumn{2}{|c|}{ [3] social } \\
\hline \multicolumn{2}{|c|}{ [4] adult } & \multicolumn{2}{|c|}{ [4] govern } & \multicolumn{2}{|c|}{ [4] legal } & \multicolumn{2}{|c|}{ [4] chang } & \multicolumn{2}{|c|}{$\begin{array}{l}{[4]} \\
\text { neighbourhood }\end{array}$} \\
\hline \multicolumn{2}{|c|}{ [5] young } & \multicolumn{2}{|c|}{ [5] privat } & \multicolumn{2}{|c|}{ [5] develop } & \multicolumn{2}{|l|}{ [5] new } & \multicolumn{2}{|c|}{ [5] characterist } \\
\hline \multicolumn{2}{|c|}{ Topic 46 } & \multicolumn{2}{|c|}{ Topic 47} & \multicolumn{2}{|c|}{ Topic 48} & \multicolumn{2}{|c|}{ Topic 49} & \multicolumn{2}{|c|}{ Topic 50 } \\
\hline \multicolumn{2}{|c|}{ Mental Health } & \multicolumn{2}{|c|}{ Public Trust } & \multicolumn{2}{|c|}{ Self-Control } & \multicolumn{2}{|c|}{$\begin{array}{c}\text { State } \\
\text { Punishment }\end{array}$} & \multicolumn{2}{|c|}{$\begin{array}{c}\text { Environmental } \\
\text { Harm }\end{array}$} \\
\hline Prev. & $\mathbf{T}_{\mathrm{b}}$ & Prev. & $\mathbf{T}_{\mathrm{b}}$ & Prev. & $\mathbf{T}_{\mathbf{b}}$ & Prev. & $\mathbf{T}_{\mathrm{b}}$ & Prev. & $\mathbf{T}_{\mathbf{b}}$ \\
\hline $1.11 \%$ & .07 & $1.89 \%$ & .24 & $2.40 \%$ & -.07 & $1.34 \%$ & -.10 & $.80 \%$ & $.62 *$ \\
\hline \multicolumn{2}{|c|}{ [1] problem } & \multicolumn{2}{|c|}{ [1] public } & [1] cont & & [1] state & & [1] envi & \\
\hline [2] treat & & [2] attit & & [2] theo & & [2] unit & & [2] harn & \\
\hline [3] healt & & [3] tow: & & [3] self & & [3] puni & & [3] envi & Iment \\
\hline [4] ment & & [4] trust & & [4] mor & & [4] puni & & [4] sout & \\
\hline [5] care & & [5] perc & & [5] test & & [5] deat & & [5] natu & \\
\hline
\end{tabular}

\section{Influence of topics}

Next, we assessed the relative prevalence of each topic within the corpus. Figure 3 displays the ten most (left) and ten least (right) prevalent topics. The most prevalent topics do not contain criminology-specific vocabulary, perhaps with the exception of the second most prevalent topic that contains words that refer to the (critical) study of the reaction to and discourse of crime (topic 15). Instead, the most prevalent topics refer to specific research designs (topic 10), the scope of the data or study (topic 36), or represent meta-vocabulary (topics 18 and 25). Topic 25 (meta-language) is the most central topic in about $4 \%$ of all abstracts, closely followed by topics 36 (UK-based research) and 15 (critical) that each dominate in slightly under $4 \%$ of all abstracts. The fourth and fifth most influential topics in our corpus represent self-report research (topic 10) or capture the methodological vocabulary specific to original research abstracts (topic 18) and are similarly important. The least prevalent topics are of a different nature. Each topic can be linked to phenomena studied in criminology such as sexual abuse (topic 20), family (topic 22), corruption (topic 13), sex work (topic 7), and environmental harm (topic 50).
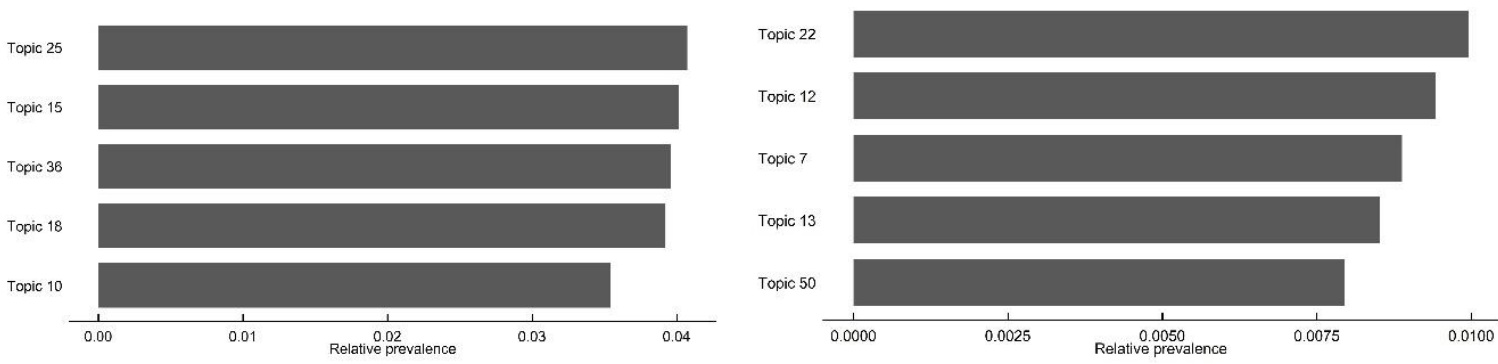

Figure 3. Overview of five most (left) and five least (right) prevalent topics $(N=11,724)$

\section{Evolution of topics}

We next turn our attention to major increases or decreases of topics within European criminology from 2001 to 2019. To do so, we assess the average relative prevalence of each topic for each year while accounting for increases in the volume of abstracts and the (dis)appearance of topics over time to identify the topics whose trajectories increased or decreased significantly. We illustrate hot and cold topics identified in this way by providing the abstract that is most representative for each of these topics. 
Although it is reasonable to assume changes in the occurrence of themes within European criminology, the majority of topics in European criminology exhibit temporal stability. That is, we did not find significant shifts in their associated trajectories, suggesting that their relative importance has remained stable over time. Some topics, however, have significantly gained importance while others have significantly lost influence over time.

We identified five topics for which the trajectories increased significantly over time, so-called hot topics in European criminology. Hot topics are significantly more addressed within European criminology since 2013. All but one of these topics reflect theoretical developments in European criminology. The trajectories of hot topics are visualized in Figure 4.

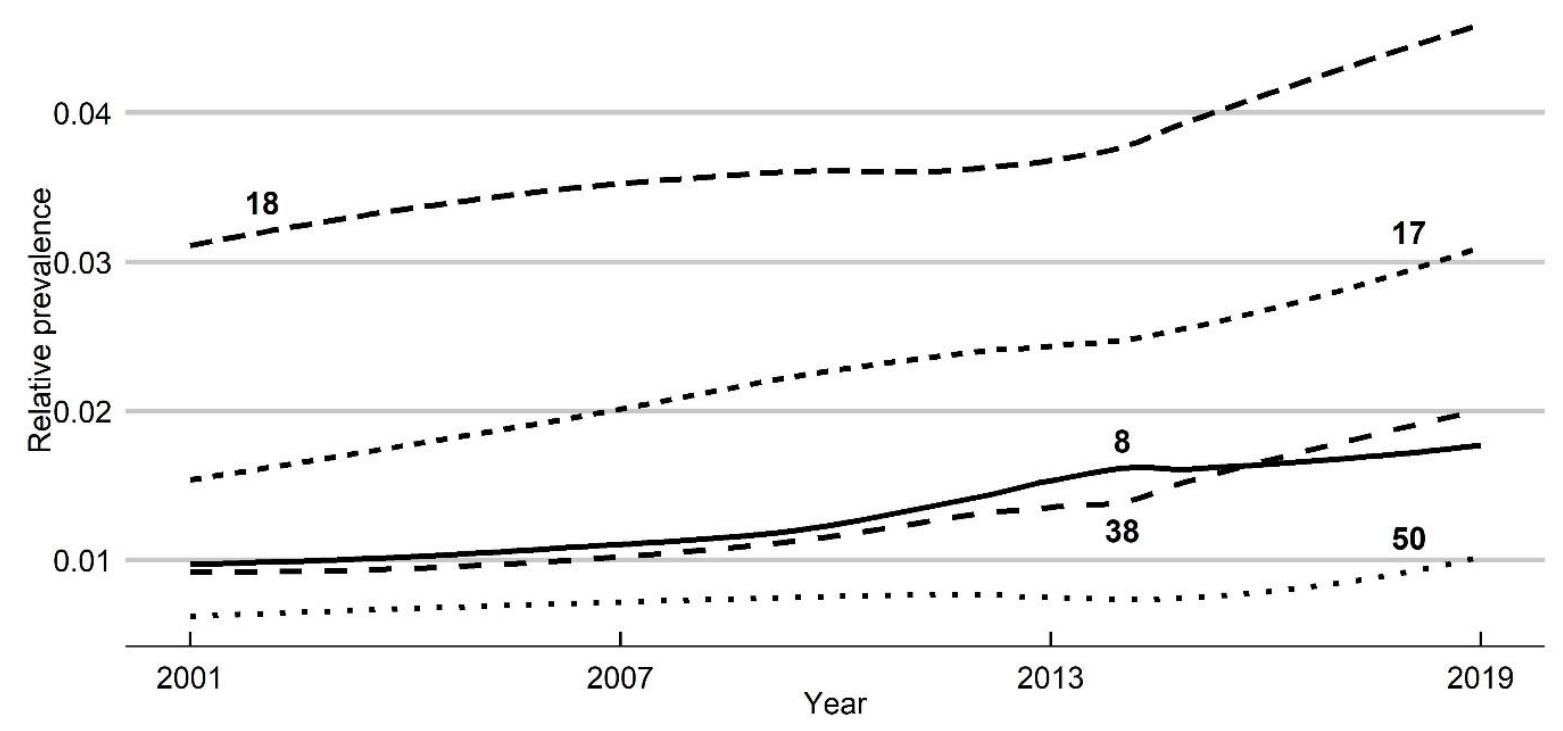

Figure 4. Trajectories of hot topics

First, we see desistance increasingly being addressed in European criminology (topic 17). For example, the abstract by Anthony Bottoms (University of Cambridge), Joanna Shapland (University of Sheffield), Deirdre Healy (University of Sheffield), and Grant Muir (University of Sheffield) entitled "Young adult recidivist male offenders and their struggles towards desistance" and presented at the 2007 Bologna conference is most representative for this topic (Bottoms et al., 2007). It is estimated that topic 17 represents approximately $68.41 \%$ of the content of this abstract (see Appendix 1). Second, European criminology increasingly engages with victims and acknowledges the importance of their involvement in various stages of the criminal justice system (topic 8). The presentation by Anna Meléndez (Universitat Autonama de Barcelona) entitled "When offenders meet their victims face to face. Changing perceptions during the mediation process? Results from research" and delivered at the 2017 Cardiff conference represents this topic best (44.06\%) (Meléndez, 2017) (see Appendix 2). Third, cybercrime is increasingly being studied (topic 38). For example, $58.87 \%$ of the abstract entitled "The Internet of Things: A hacking wonderland" by Tine Munk (Middlesex University) and presented at the 2017 Cardiff deals with this topic (Munk, 2017) (see Appendix 3). Fourth, the debate on environmental harm and crime has emerged and resulted in the foundation of green criminology research within European criminology (topic 50). Although in general terms, interest in this topic is modest as this topic is the least prevalent topic in the entire corpus. This topic is most clearly illustrated by Robert White's (University of Tasmania) presentation entitled "Studying environmental crime: The foundations of green criminology and beyond" and delivered at the 2011 Vilnius conference (50.10\%) (White, 2011) (see Appendix 4). Finally, we notice that in recent years abstracts increasingly follow standardized formats 
with specific theoretical, methodological and meta-scientific vocabulary. This is clearly reflected in topic 18 which captures the methodological vocabulary increasingly used in abstracts reporting on original empirical research. For example, topic 18 represents an estimated 52.45\% of the content of the abstract by Gunda Woessner (Max Planck Institute for Foreign and International Criminal Law) entitled "Measuring Violence: An Empirical Approach to Capture the Phenomenology and Nature of Violence" and presented at the 2019 Ghent Conference (Woessner, 2019) (see Appendix 5).

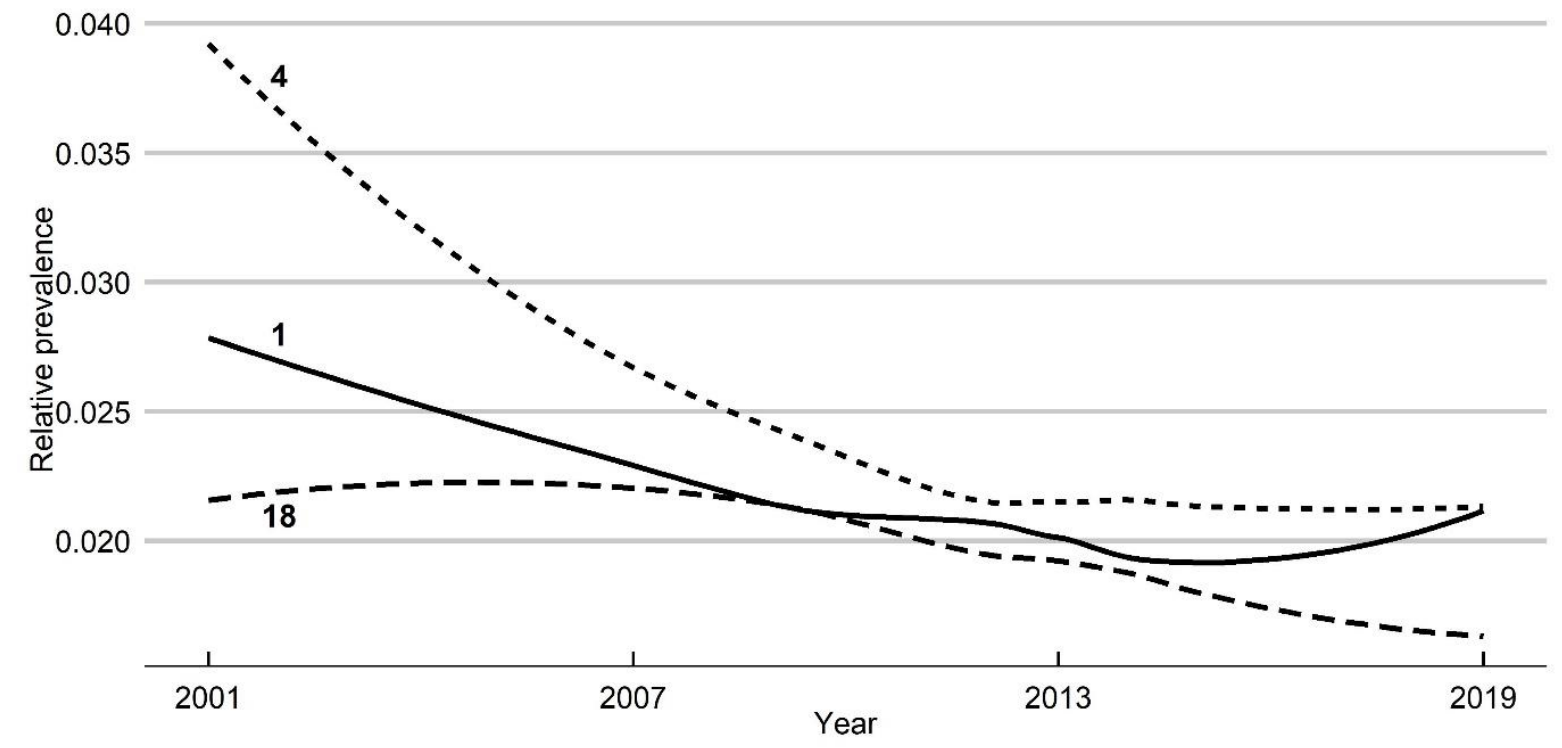

Figure 5. Trajectories of cold topics

The three topics that exhibit significant decreasing trajectories over time-cold topics-indicate that homicide rates, hate crimes, and sexual offending were gradually less addressed in European criminology (Figure 5). First, homicide rates as a topic was frequently addressed at annual conferences in the 2000s but interest with this topic disappeared from 2013 onwards and reached an all-time low in 2019 (topic 4). Nonetheless, a presentation delivered at the 2019 Ghent conference by Rannveig Thorisdottir (Reykjavik Metropolitan Police), and Jonas Orri Jonasson (Reykjavik Metropolitan Police) and entitled "The 'Nordic Homicide from Past to Present' project: Icelandic Homicides in the 20th century" represents this topic best (61.80\%) (Thorisdottir and Jonasson, 2019) (see Appendix 6). Second, interest with hate crimes decayed over time (topic 1). Although this topic was regularly addressed in the early 2000s, interest reached a low in the mid-2010s but gradually picked up again afterwards. Jenita Rauta (Police University College of Finland), and Jarmo Houtsonen (Police University College of Finland) authored the quintessential hate crime abstract entitled "The Finnish hate crime monitoring system" and presented at the 2017 Cardiff conference (31.76\%) (Rauta and Houtsonen, 2017) (see Appendix 7). Finally, fewer abstracts covered sexual offending research (topic 32). Despite a peak of interest in sexual offending around 2005, interest dropped and reached a low in 2019. This cold topic is best represented by an abstract by Arjan Blokland (Netherlands Institute for the Study of Crime and Law Enforcement), Torbjorn Skardhamar (Statistics Norway), Anton van Wijk (Advice and Research Group Beke), and Christine Friestad (Ulleva University Hospital) entitled "Offending diversity in sex offenders: Comparing different types of sex offenders using Dutch and Norwegian police data" and presented at the 2008 Edinburgh conference (63.26\%) (Blokland et al., 2008) (see Appendix 8). 


\section{DISCUSSION AND CONCLUSION}

Applying topic modelling to determine the state of affairs of European criminology is a new approach to the debate on what European criminology is about. We applied topic modelling to analyse the content of 11,724 abstracts accepted for presentation at the annual conferences of the European Society of Criminology between 2001 and 2019, a period in which European criminology saw considerable growth and institutionalization as evidenced by the steep increase in presentations held at the annual conferences of the European Society of Criminology. We analysed the trends in the 50 topics that emerged from a text corpus representing a state of affairs of European criminology to explore changes in European criminological inquiry in the past 19 years.

Based on our results, the main question underpinning this study — What is European criminology? — can be answered in 50 topics. Some topics are more influential than others but a clear dominance of one or more topics could not be established. Of the five most prevalent topics, we identified two abstract general topics that capture the vocabulary of 'doing criminology' (topic 25) and the methodological vocabulary specific to original research abstracts accepted for presentation at the annual conferences of the European Society of Criminology (topic 18). In fact, the most dominant topic in our corpus captures the meta-language and vocabulary of research in general without being specific to criminological research (topic 25). The content of three other most prevalent topics refer to specific study designs (topic 10), research approaches (topic 15), and a specific study context (topic 36). Combined, these five topics represent approximately a fifth of the variation in the content of the abstracts we analysed. None of the five most influential topics we identified represent a specific approach or certain school of thought within criminology. The presence of a topic referring to the (qualitative) critical study of the reaction to crime in addition to a topic that represents (quantitative) self-report research could be indicative of the width of research approaches in European criminology and suggests the absence of a theoretical or methodological domination in European criminology. However, this width is not reflected in terms of the national scope of studies, despite what some may have suggested earlier (Baars-Schuyt, 2001; Smith, 2014). One of the most influential topics, UK-based research (topic 36), clearly represents a dominance of research specific to the UK and UK data. This should not come as a surprise as we have established that for one in five abstracts approved for presentation at ESC conferences the first author is affiliated with a UK institution. However, research pertinent to or focused on Central European countries also emerged as a topic from our analysis (topic 31). In the same vein, even though European criminology is argued to be a collaborative project that involves authors from diverse geographical orientations, our analysis clearly demonstrates that it is dominated by scholars based in just five countries of which UKbased authors alone are responsible for one in five abstract contributions. Topics representing distinctive research themes and phenomena studied within criminology, such as research into sex work (topic 7), corruption (topic 13), sexual abuse (topic 20), the family (topic 22), and environmental harm (topic 50), are among the five least influential within the corpus we considered.

Most of the topics within European criminology are evenly distributed in the last 19 years. This suggests that European criminology as a field exhibits a certain degree of stability. Nevertheless, we identified eight topics that showed a significant increase or decrease in their trajectories over time. Topics on the rise for the last 19 years represent specific research themes such as victims (topic 8), desistance (topic 17), cybercrime (topic 38), and environmental harm (topic 50) or demonstrate the adoption of a methodological vocabulary that is specific to original research abstracts at the ESC conferences (topic 18). Some of these hot topics at the annual conferences of the European Society of Criminology coincide with societal changes such our increased concern for the climate crisis (topic 50), and the dominance of the internet, social media, and new technologies in our daily lives (topic 38). Other topics hint at a shift in the praxis of European criminology and suggest that original research is becoming increasingly 
important in European criminology (topic 18). Researchers attending the annual conferences of the European Society of Criminology increasingly report on original research activities rather than that they present theoretical arguments or positions, and in their abstracts authors increasingly resort to writing about their methodology, data, and analytical tools and techniques. However, this result could also be an artefact of our analysis of conference contributions and therefore a limitation of our approach. Conference settings might simply favour presenting original research instead of delivering theoretical arguments. As a result, in our representation of European criminology we might overemphasize the importance of original research in European criminology. Nevertheless, the overall influence of these trending topics in European criminology should not be overstated as there prevalence in the corpus remains limited.

Topics for which the interest has significantly declined in the last 19 years have been hate crime (topic 1), homicide rates (topic 4), and sexual offending (topic 32). As a result, it seems that a substantive change in focus has taken place over the last 19 years within European criminology and that the increased interest in some topics comes at the expense of the interest in other topics. The decline of homicide research as a topic in European criminology can perhaps be explained by a stronger homicide research tradition in American criminology embodied by a dedicated US-centered homicide research working group and specific conferences addressing homicide research (Block and Block, 1997 see also the editorial board of Homicide Studies). The decay of sexual offending in European criminology, however, is more difficult to explain as we have no clear indications to believe that this topic would be of lesser interest to European criminology, even though our analysis seem to suggest this. Perhaps, attendance by those who engage in sexual offending research has declined due to the emergence of specialized sexual offending conferences such as the meetings of the International Association for the Treatment of Sexual Offenders and the international conferences on the Survivors of Rape. If this is the case, this could illustrate the challenge for criminology in general and European criminology in particular that was identified by Bruinsma (2016). In his 2015 presidential address, Bruinsma (2016: 667) characterized European criminology as a fragmented field with many competitive groups of scholars and schools of thought that are preoccupied with studying their distinct topic and of which the members prefer to publish in specialty journals, attend specialized conferences, and prefer to engage in discussions with peers within their expert working groups. Though specialization can be very efficient for the development of the activities within those schools of thought and is increasingly becoming important for advancing the careers of young scholars, it also runs the risk of muting the conversation within criminology at large. It can even lead us to challenge the added value of (European) criminology (conferences). If as a community we decide to specialize within our subdiscipline and focus exclusively on our specialty topic or engage only with research and researchers active in our preferred subdiscipline, we might look for peers active in those specific domains, regardless if these peers are or consider themselves criminologists. However, this is not a call to reconsider interdisciplinary research collaboration. Instead, it is an observation that a loss of conversation across subdisciplinary boundaries within criminology or exclusive scholarly engagement outside criminology runs the risk of criminologists losing command over their domain and criminologists becoming kings without a country (again) (Vander Beken, 2018, 2019).

Following up on the results of this study and those of similar studies (e.g., Cohn and Iratzoqui, 2015; Farrington et al., 2019; Smith, 2014), we have identified five avenues for future research. First, it could be interesting to look into the topics addressed at the annual conferences of the American Society of Criminology, the British Society of Criminology, the Australian and New Zealand (ANZAC) Society of Criminology, and the Asian Criminological Society, and examine their state of affairs. Second, working from there it would be interesting to compare the differences and similarities of topics addressed in European criminology with those addressed in American criminology, British criminology, 
ANZAC criminology, and Asian criminology. Third, another option would be to go in further detail and study aspects not optimally covered in this study, such as why certain topics became hot and cold. A better understanding of these shifts and their underlying factors could be useful to further the development of European criminology. For example, the November 2015 Paris attacks and the March 2016 Brussel bombings could have spurred terror-related research. Fourth, building on Smith (2014), topic modelling could also be applied to study the European Journal of Criminology and complement our analysis of European criminology. Finally, it would be interesting to apply topic modelling to criminology as a discipline and, for example, study all abstracts linked to criminology and indexed in Web of Science or Google Scholar to come to a state of affairs of criminology research in general.

The annual conferences of the European Society of Criminology are the living memory of European criminology. As such, our analysis provides an insight into the width and depth of European criminology (Smith, 2014). Although European criminology is clearly broader than what is presented at the annual conferences of the ESC, our analysis demonstrates where European criminology is coming from and where it might be heading to.

\section{REFERENCES}

APA Science Student Council (2007) Why It's Important For You To Present Your Data at Scientific Conferences. Psychological Science Agenda, November. Available at: https://www.apa.org/science/about/psa/2007/11/student-council-1 (accessed 10 June 2020).

Baars-Schuyt A (2001) Overview of Criminology in Europe. European Journal on Criminal Policy and Research 9(3): 301-313.

Blei DM and Lafferty JD (2007) A correlated topic model of Science. The Annals of Applied Statistics $1(1): 17-35$

Blei DM and Lafferty JD (2009) Topic Models. In Srivastava A and Sahami M (eds) Text Mining: Classification, Clustering, and Applications. London: Chapman \& Hall/CRC, pp. 328.

Block R and Block CR (1997) The Homicide Research Working Group: A History and Description. Homicide Studies 1(1): 11-16.

Blokland A, Skardhamar T, van Wijk A and Friestad C (2008) Offending diversity in sex offenders: Comparing different types of sex offenders using Dutch and Norwegian police data. Paper presented at the EuroCrim, Edinburgh.

Body-Gendrot S, Hough M, Kerezsi K, Lévy R and Snacken S (eds) (2014) The Routledge Handbook of European Criminology. London: Routledge.

Bottoms AE, Shapland J, Healy D and Muir G (2007) Young adult recidivist male offenders and their struggles towards desistance. Paper presented at the EuroCrim, Bologna.

Bruinsma G (2016) Proliferation of crime causation theories in an era of fragmentation: Reflections on the current state of criminological theory. European Journal of Criminology 13(6): 659-676.

Calhoun C (ed) (2007) Sociology in America: A History. Chicago, IL: The University of Chicago Press.

Cohn EG and Iratzoqui A (2015) The Most Cited Scholars in Five International Criminology Journals, 2006-10. The British Journal of Criminology 56(3): 602-623

Daenekindt S and Huisman J (2020) Mapping the scattered field of research on higher education. A correlated topic model of 17,000 articles, 1991-2018. Higher Education.

Dayé C (2018) A Systematic View on the Use of History for Current Debates in Sociology, and on the Potential and Problems of a Historical Epistemology of Sociology. The American Sociologist 49(4): 520-547.

DiMaggio P, Nag M and Blei D (2013) Exploiting affinities between topic modeling and the sociological perspective on culture: Application to newspaper coverage of U.S. government arts funding. Poetics 41(6): 570-606. 
Farrington DP, Cohn EG and Iratzoqui A (2019) Who Are the Most-Cited Scholars in Asian Criminology Compared with Australia, New Zealand, North America, and Europe? Asian Journal of Criminology 14(1): 61-76.

Giordan G, Saint-Blancat C and Sbalchiero S (2018) Exploring the History of American Sociology Through Topic Modelling. In Tuzzi A (ed) Tracing the Life Cycle of Ideas in the Humanities and Social Sciences. Cham: Springer International Publishing, pp.45-64.

Griffiths TL and Steyvers M (2004). Finding scientific topics. Proceedings of the National Academy of Sciences 101(suppl 1): 5228-5235.

Haen-Marshall I (2001) The Criminological Enterprise in Europe and the United States: A Contextual Exploration. European Journal on Criminal Policy and Research 9(3): 235-257.

Killias M and Rau W (2000) The European Sourcebook of Crime and Criminal Justice Statistics: A New Tool in Assessing Crime and Policy Issues in Comparative and Empirical Perspective. European Journal on Criminal Policy and Research 8(1): 3-12.

Knepper P (2018) What the European Journal of Criminology contributes to European criminology. European Journal of Criminology 15(6): 655-657.

McAra L (2019) Why the European Society of Criminology matters. Newsletter of the European Society of Criminology 18(3): 2-4.

Meléndez A (2017) When offenders meet their victims face to face. Changing perceptions during the mediation process? Results from research. Paper presented at the EuroCrim, Cardiff.

Mohr JW and Bogdanov P (2013) Introduction-Topic models: What they are and why they matter. Poetics 41(6): 545-569

Munk T (2017) The Internet of Things: A hacking wonderland. Paper presented at the EuroCrim, Cardiff.

Porter MF (2001) Snowball: A language for stemming algorithms. Available at: http://snowball.tartarus.org/texts/introduction.html (accessed 10 June 2020).

Rauta J and Houtsonen J (2017) The Finnish hate crime monitoring system. Paper presented at the EuroCrim, Cardiff.

Ruggiero V, South N and Taylor I (1998) Introduction. Towards a European Criminological Community. In Ruggiero V, South N and Taylor I (eds) The New European Criminology: Crime and Social Order in Europe. London: Routledge, pp.1-15.

Schneider HJ (2001) In Need of a European Criminology. European Journal on Criminal Policy and Research 9(3): 331-336.

Seippel $\varnothing$ (2018) Topics and trends: 30 years of sociology of sport. European Journal for Sport and Society 15(3): 288-307.

Smith DJ (2004) Editorial: Criminology and the Wider Europe. European Journal of Criminology 1(1): 515.

Smith DJ (2014) Wider and deeper: The future of criminology in Europe. European Journal of Criminology 11(1): 3-22.

Steyvers M and Griffiths TL (2014) Probabilistic Topic Models. In Lindauer TK, McNamara DS and Kintsch W (eds) Handbook of Latent Semantic Analysis. London: Routledge, pp.424-440.

Tham H (2001) The Need for a European Criminology? European Journal on Criminal Policy and Research 9(3): 345-347.

Thorisdottir R and Jonasson JO (2019) The 'Nordic Homicide from Past to Present' project: Icelandic Homicides in the 20th century. Paper presented at the EuroCrim, Ghent.

Tonry M (2015) European Criminology and the ESC--Continental Cures for American Ailments. Newsletter of the European Society of Criminology 14(2): 2-3.

Vander Beken T (2018) Open Criminology. Newsletter of the European Society of Criminology 17(3): 23.

Vander Beken T (2019) Futures of European Criminology. Newsletter of the European Society of Criminology 18(2): 2-4.

White R (2011) Studying environmental crime: The foundations of green criminology and beyond. Paper presented at the EuroCrim, Vilnius. 
Woessner G (2019) Measuring Violence: An Empirical Approach to Capture the Phenomenology and Nature of Violence. Paper presented at the EuroCrim, Ghent.

\section{APPENDIX}

\section{Appendix 1. Abstract Bottoms, Shapland, Healy and Muir (2007)}

"This is an interim paper arising from the Sheffield Desistance Study, which focuses on 113 young adult male recidivists, aged about 20 at first interview. Participants are being studied longitudinally, with an intended four interviews at 9-12 month intervals. At first interview, the majority of respondents expressed a firm intention to desist; but subsequent interviews showed that expressed desistance/non-desistance intentions frequently changed, in both directions. The paper examines both stability and change in desistance/non-desistance intentions, in the period from the first to the fourth interview. Expressed intentions are related to the immediate social and situational context, as well as to the changing trajectories of the young men's lives over the relevant period. Exploration of such issues on a longitudinal basis, and using a mixed quantitative and qualitative methodology, sheds new light on the ongoing process of desistance/non-desistance, and the personal and social struggles that are often involved in serious attempts to desist. Hence, the study contributes to the growing interest in human agency in desistance studies." (Bottoms et al., 2007)

\section{Appendix 2. Abstract Meléndez (2017)}

"Meeting the other face to face can be a challenging experience for both victim and offender. In this research, the 40 post-test questionnaires completed by the offenders after mediation included some questions about feelings, attitudes and perceptions related to meeting the person they had injured. It was possible to analyse how they felt and what meeting their victims had meant for them. One of the aims was to find out whether offenders were able to understand the impact of the offence on the victims after having listened to them. Another aim was to identify a positive movement or mutual understanding between victims and offenders. With regard to understanding some were not able to comprehend, while others were able, after having interacted with the victim, to understand how they felt after having been harmed. These outcomes can be seen as somewhat positive because almost half of the sample were able to understand their victims after having spoken with them. However, there were still some who were doubtful and others unable to comprehend how the other party felt." (Meléndez, 2017)

\section{Appendix 3. Abstract Munk (2017)}

"The growing use of computer technologies, devices and communication platforms in everyday life creates a paradox. The Internet-of-Things based on interconnected devices makes everyday life smarter, more convenient and more efficient and everyone benefits from this technological development albeit with little understanding of the security concerns. The increased use of the Internet-of-Things migrates away from the laptop, the tablet and the smartphone, and the security features on these internet linked devices such as GPSs, VRDs, cameras, cars, businesses and home automation, sensors and alarm systems lag far behind. Smart devices or the Internetof-Things are not sufficiently updated and security measures are lacking which creates a hacking wonderland for a number of actors. The lack of security in relation to the Internet-ofThings was exploited by the innovative 2016 Dyn attack. This was an unprecedented large-scale attack which brought down several well-known companies worldwide simultaneous using an Internet-of-Things botnet. This paper will discuss the Dyn attack, the security problems related to the Internet-of-Things, the lack of regulation and awareness of the security threat. Moreover, the paper will also discuss the use of the Internet of-Things ability to [sic]" (Munk, 2017) 


\section{Appendix 4. Abstract White (2011)}

"The aim of this paper is to chart out the diverse theoretical, political and methodological directions that the study of environmental crime has taken over the past two decades. The paper provides a systematic reflection on who is doing what when it comes to the investigation of environmental issues from a criminological perspective. As part of this, it examines where differences lie and where analyses overlap among those with an interest in the study of environmental crime. Five key frameworks of analysis are identified: green criminology, ecoglobal criminology, conservation criminology, environmental criminology, and environmental cultural criminology. After discussing the nature and content of these specific orientations, the paper concludes by raising questions about whose voices are yet to be heard, why this is the case, and what might be done about it. Rather than presenting the frameworks as in competition, the intention of the paper is to identify particular contextual strengths (and limitations) of each approach to studying environmental crime." (White, 2011)

\section{Appendix 5. Abstract Woessner (2019)}

"This paper provides an overview of the empirical challenges and considerations associated with violence research. Moreover, the empirical operationalisation of the subject and scope of the Violence Research Lab will be presented, with a particular focus given to its applied research techniques and underlying considerations. The Violence Research Lab encompasses both a quantitative approach (a case file analysis) and a qualitative approach (to investigate unreported violence). These methods are used to obtain a comprehensive picture of what violence looks like when its normative corset is removed, of how it can be explained and of how different levels of severity impact perpetrators and victims. This necessarily incorporates analyses of contextual, social and psychosocial features. In addition, it is essential to develop parameters that allow for the measuring of the intensity and severity of violence. Results from the pilot phase of the data collection process will be presented." (Woessner, 2019)

\section{Appendix 6. Abstract Thorisdottir and Jonasson (2019)}

"In recent decades homicide rates in developed countries have decreased along with other types of crimes. Compared to other Nordic countries homicide rates in Iceland are similar to the rate per capita in the other countries apart from Finland. The aim of the Nordic Homicide project is to develop a coding manual to be better able to compare trends in time and space between the Nordic countries in a standardized manner. This study focuses on Icelandic homicide rates from the beginning of the $20^{\text {th }}$ century until 2018. The paper focuses on answering if and then how the homicide rate has changed during the 20th century. Data from two different data sources was analyzed Icelandic court archives and the Icelandic police database. Cases were coded according to the EHM standard. The results show that homicide rates in Iceland increased after 1970. The average went from 0.3 cases each year per 100.000 inhabitants to 0.7 cases in the 1970s and onwards. One of the similarities found between the cases was that the offender was most often under the influence of alcohol (and in later years drugs) when committing the crime and the perpetrators were usually men." (Thorisdottir and Jonasson, 2019)

\section{Appendix 7. Abstract Rauta and Houtsonen (2017)}

"Annual reports on racist crime in Finland have been published by the Police University College and the Ministry of Interior's Police Department since 1998. In 2009, the system of compiling information on racist crime was developed into a more comprehensive system of monitoring hate crime. Since then, reports on hate crimes reported to the police in Finland have been compiled annually by the Police University College. This presentation gives an overview of suspected hate crimes reported to the police in 2016. The Criminal Code of Finland does not 
include a definition of hate crime, only as an aggravated circumstance. For the purpose of the reports, hate crime has been defined as a crime against a person, group, somebody's property, institution, or a representative of these, motivated by prejudice or hostility towards the victim's real or perceived ethnic or national origin, religion or belief, sexual orientation, transgender identity or appearance, or disability In addition to the annual hate crime report, the Police University College has an ongoing research which aims to examine how crimes with bias motives are negotiated on different levels in the criminal justice system and how these biases are taken into account by the court." (Rauta and Houtsonen, 2017)

\section{Appendix 8. Abstract Blokland, Skardhamar, van Wijk and Friestad (2008)}

"In this paper we analyse offending diversity in the criminal careers of sexual offenders. Prior research on sex offending usually distinguishes between types of offenders (hands-off/hands-on; peer abusers/child abusers) based on the nature of the sexual offence committed. Other sexual offender typologies (e.g. Becker \& Kaplan, 1988; Seto \& Barbaree, 1997) distinguish specialists from generalists based on the variety of offences offenders commit. Here we combine these two approaches and assess offending diversity in sexual offenders arrested for different types of sex offences. Using longitudinal police data from both The Netherlands and Norway, we relate the type of sex offence offenders were first arrested for to the diversity of offending in their subsequent criminal careers. Differentiating between diversity in sexual and non-sexual offending our results also reflect on the issue of cross-over." (Blokland et al., 2008) 